Chapter 8

\title{
Bioavailability of High Molecular Weight Polycyclic Aromatic Hydrocarbons Using Renewable Resources
}

\author{
Olusola Solomon Amodu, Tunde Victor Ojumu and \\ Seteno Karabo Obed Ntwampe
}

Additional information is available at the end of the chapter

http://dx.doi.org/10.5772/54727

\section{Introduction}

Polycyclic aromatic hydrocarbons (PAHs) are the world's largest class of carcinogens known to date, not only because of their ability to cause gene mutation and cancer, but due to their persistency in the environment. They are particularly recalcitrant due to their molecular weight, hydrophobic nature and thus, accumulate in various matrices in the environment.

PAHs, also known as polyarenes or polynuclear aromatic hydrocarbons, are formed and released into the environment through natural and anthropogenic sources. Natural sources include volcanoes and forest fires while anthropogenic sources include, majorly, incomplete combustion of fossil fuels, wood burning, municipal and industrial waste incineration. PAHs containing two or three fused benzene rings are classified as low molecular weight (LMW) PAHs and are more water soluble while those with four or more benzene rings are referred to as high molecular weight (HMW) PAHs. They tend to adsorb onto soil and sediment thus, making them recalcitrant in the environment. Sixteen of these organic compounds have been identified as priority pollutants due to their hazardous properties, with HMW PAHs being considered as potential human carcinogens, by the United State Environmental Protection Agency [1].

The cost of biodegradation technology and the low bioavailability including mass transfer limitations of PAHs, especially those with high molecular weight, from several matrices into the aqueous phase for effective enzyme-based microbial biodegradation still constitute major challenges. However, current research efforts have focused on the combined use of biosurfactants and enzymes produced from renewable resources such as agricultural by-products and/ or agro-industrial waste, through assisted biostimulation and bioaugmentation, for biodegra- 
dation of PAHs. Such methods are relatively inexpensive and less invasive as compared to physico-chemical remediation processes [2-4]. The application of crude biosurfactants produced by Pseudomonas ssp., Rhodococcus ssp. and several others, have been observed to achieve a high mobilization rate of PAHs from contaminated environmental matrices $[5,6]$.

The synergistic effect of biostimulation combined with bioaugmentation using fungal strains of Rhizopus spp., Penicillium spp. and Aspergillus spp., isolated from PAH contaminated soil, significantly improve the overall bioavailability for the biodegradation of PAHs in comparison to biostimulation alone [7]. Additionally, several other renewable resources have been used as sources of both carbon and nitrogen by several microorganisms during the expression of biosurfactants thus enhancing PAH bioavailability and enzymatic biodegradation [8-11]. This review describes the environmental behavior of PAHs, and how it affects bioavailability. It also examines the effectiveness of microorganisms used in the production of crude biosurfactants for the biodegradation of HMW PAHs rather than the direct application of refined extracts, with a view to minimize the cost associated with enzymatic biodegradation. The chapter further discusses the effects of bioavailability on the biodegradation of HMW PAHs; bioavailability kinetics to quantitatively estimate PAHs bioavailability using different microorganisms; and enhanced biodegradation of PAHs using crude biosurfactants from renewable resources.

\section{Bioavailability of HMW PAHs}

\subsection{PAHs bioavailability - Definitions and intrinsic factors}

Polycyclic aromatic hydrocarbon mobilization and biodegradation are contingent upon their bioavailability from various matrices. Given the legal and regulatory implications of the bioavailability concept as part of a risk assessment framework, the term must be clearly understood in order to establish the minimum level permissible for contaminants like PAHs in the environment. The understanding of bioavailability is also important to be able to assess and evaluate the overall success of PAHs biodegradation. Researchers, however, differ in their opinion as to what the exact definition of bioavailability should be [12].

The following definitions for bioavailability were compiled in Technical Reports published by the European Centre for Ecotoxicology and Toxicology of Chemicals [13] and the United State National Research Council [14]: (i) "The ability of a substance to interact with the biosystem; (ii) "The fraction of the contaminants in the environment that is potentially available for biological action" [15]; (iii) "The amount/percentage of a compound that is actually taken up by an organism as the outcome of a dynamic equilibrium of organism-bound sorption processes, and soil particle-related exchange processes, all in relation to a dynamic set of environmental conditions" [16]; (iv) "The fraction of a chemical accessible to an organism for absorption, the rate at which a substance is absorbed into a living system, or a measure of the potential to cause a toxic effect". In pharmacology and toxicology, the term relates to the systemic availability of a xenobiotic after intravenous or oral dosing [17]. Although these concepts are useful, making direct parallels from the pharmacological usage to contaminants in soil and sediment or biota can be problematic. For example, microorganisms do not have a 
digestive tract, target organs, or a circulatory system [13]. These concepts may also not be appropriate as contaminants in soil or aquatic environments, being controlled by, for example, the rate of desorption and mobilization from solid matrices, are often continuously supplied to organisms gradually rather than at an acute dose. Environmental scientists often consider bioavailability to represent the accessibility of a soil-bound chemical for assimilation and possible toxicity $[18,19]$ and thus, have tried to adapt the use of bioavailability concept when considering human exposure to soil-borne contaminants. For example, Ruby [20] including Kramer and Ryan [21] suggested that the bioavailable portion is the amount of compound that is removed from soil through desorption processes under physiological conditions. Another view of bioavailability is represented by the contaminant crossing a cell membrane, entering a cell, and becoming available at a site of biological activity. Others might think of bioavailability more specifically in terms of contaminant binding to or release from a solid phase.

Obviously, the different definitions of the term bioavailability by scientists in various disciplines are capable of causing semantic confusion and thus, garner more attention than proffering solution to its challenges. The authors, in this chapter, have compiled these opinions in order to present a simple and workable definition to the term bioavailability as it is important to estimateF; the extent of contaminants desorption from the sorbed phase, the non-aqueous phase residue as against the minimum level required in the environment for such contaminants, and thus assessing the overall success of biodegradation. Considering these opinions about bioavailability, two words are common to almost all, which are; uptake or absorbed and available. Based on this observation, bioavailability can be defined as the amount of available contaminants in the environment that can be absorbed by microorganisms and /or biological products. Other clauses such as the fraction of contaminants taken up or absorbed, the fraction of contaminant that is potentially available, the mobilization or transportation of contaminants from the sorbed phase, the amount desorbed from the soil matrices, etc., which are often included in the definition of bioavailability and thus causing confusion, are intrinsic factors or features of bioavailability. However, these intrinsic factors are influenced by the physicochemical properties of the contaminants and those of the sorbent.

Hence, studies on bioavailability are very crucial in order to link the quantity of PAHs taken up by microorganism with the actual amounts that are available to cause adverse effects in the environment. Many factors have been known to affect PAH bioavailability, which are $[12,22,23]$;

- Physical and chemical properties of PAHs,

- Soil properties (soil organic matter, dissolved organic matter, moisture content, etc.),

- Aging of PAHs in soil and receptor microorganism.

\subsection{Effects of physical and chemical properties of PAHs on bioavailability}

Bioavailability is influenced by the molecular structure and size of PAHs. LMW PAHs are removed faster by physico-chemical and biological processes due to their higher solubility, volatility and the ability of many microorganisms to use them as sole carbon sources in comparison to the HMW PAHs [24]. Bioavailability changes with time and weathering [25]. Aging is a cen- 
tral part concerning availability and refers to the process of organic compounds in soil becoming less susceptible to degradation, extractability and other related processes in a time dependent manner [26, 18]. Aging increases sorption propensity of soil contaminants making them more recalcitrant to diffusion and mobility which consequently lead to low bioavailability. Both the physico-chemical properties of the contaminant and the soil characteristics influence aging, which may include several steps and processes such as oxidation thus incorporating the contaminant into natural organic matter [27, 28], slow diffusion into small pores and absorption into organic matter, or entrapment due to the formation of semi-rigid films around non-aqueous-phase liquids (NAPL) with a high resistance toward NAPL-water mass transfer [29].

\subsection{Effects of soil or sediment and dredging properties on PAHs bioavailability}

Soil properties such as organic matter content, soil texture, soil depth, particle size, $\mathrm{pH}$, porosity, intrinsic permeability, liquid limit, and cation exchange capacity, influence PAH bioavailability. Soil properties can vary greatly from one region to another. They can even vary within the same region spatially and with depth [30]. Microorganisms have different levels of tolerance to these factors, which affect their growth and other metabolic activities. Soil structure such as aggregation has been found to decrease PAH availability through physical sequestration of PAHs in the interior of aggregates [31]. For instance, Nam et al. [32] found that PAH bioavailability to phenanthrene degraders declined with time in soils which had more than two percent organic matter. Hundal et al. [33] reported on the retention of large amounts of phenanthrene by smectite clays. Yang et al. [34] investigated the impact of soil organic matter on PAHs distribution in soils and reported that when the soil organic matter was increased from 0.2 to $7.1 \%$ the average non-bioavailable amount of acenaphthene, anthracene, fluoranthene, and pyrene were almost tripled from 436.9 to $1205.8 \mathrm{ng} / \mathrm{g}$.

\subsection{Effects of mass transfer on bioavailability of HMW PAHs}

The overall PAHs biodegradation can be conceptually divided into the following steps: desorption to the eqeuous phase; mass transfer to biologically accessible regions; and biological uptake and transformation [35, 18], as shown in Figure 1. These steps occur sequencially, such that the overall biodegradation rate can be controlled by any of these steps. Given the sequential nature of the process, the impact of desorption rate on overall biodegradation is expected to be greatest in the case where biodegradation rates are higher relative to desorption rates. This occurs when the active microorganisms are capable of high biodegradation rates and either the media is porous thus having a high capacity for the solute, or media has large diffusion distances [36,37]. Based on this, it is important to examine how the physical morphology of surface and subsurface soils can impact the biodegradation of sorbed organic chemicals. Naturally, soil contains porous particles of different sizes, many of which are smaller than the size of microorganisms. For example, analysis of one of the coarser sand sizes from the Borden aquifer in Ontario (Canada), indicated that, roughly 50\% of the intraparticle pore volume resides in pores that are less than $0.1 \mu \mathrm{m}$ in diameter [38]. 


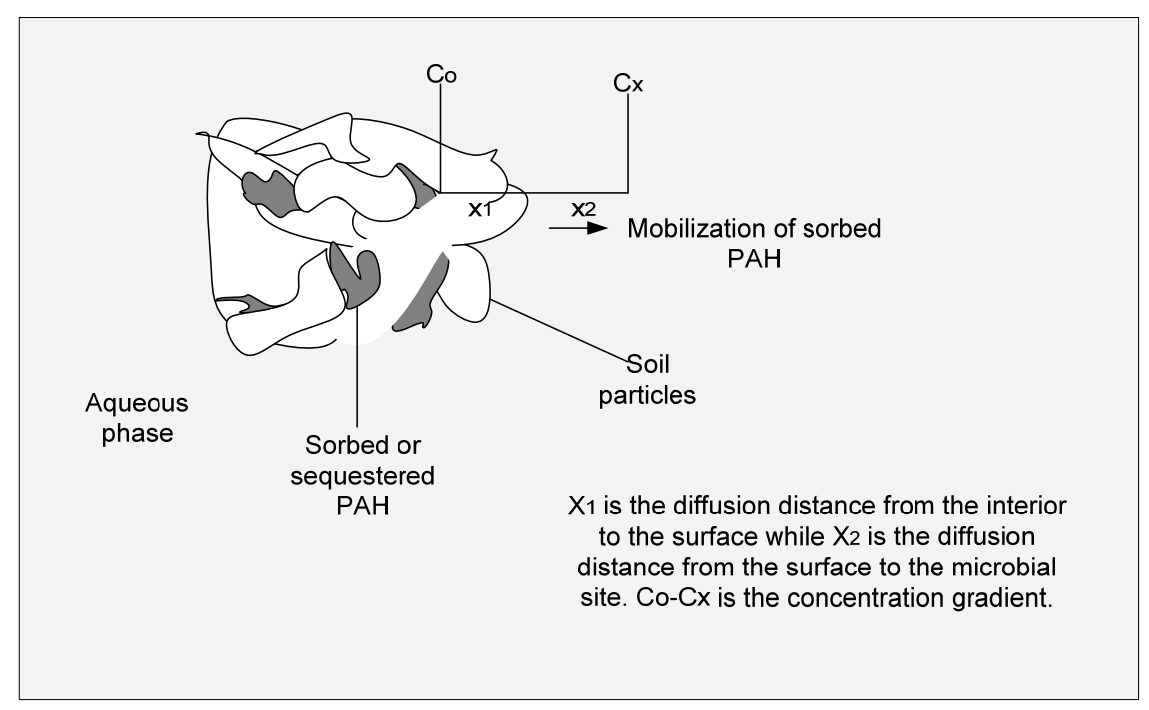

Figure 1. Diffusion of entrapped PAH out of soil micropores into aqueous phase to become available to microorganism.

Pores with diameter larger than $1 \mu \mathrm{m}$ comprised about $12 \%$ of the total pore space, and only about $5 \%$ of the pore volume was attributed to pores larger than $2 \mu \mathrm{m}$. Considering that most indigenous bacteria found in soil are 0.5 to $1.0 \mu \mathrm{m}$ in diameter [39], bacteria will be physically excluded from attaching to intraparticle pores of these grains. The mean diameter of intraparticle pores occupied by bacteria has been estimated to be typically larger than $2 \mu \mathrm{m}$ [40], and this is likely to be larger than intraparticle porespaces of many natural sorbent solids. However, for those pores which are accessible to bacteria, slow mass transfer of contaminants from the pore interior as well as from the pore surface can limit the extent of microbial growth and consequently biodegradation.

\section{Kinetic models and assessment of bioavailability of PAHs}

\subsection{First-order kinetics}

Biodegradation rate of PAHs in the aqueous phase and the rate constant $(k)$ can be determined using the reaction rate expression as follows:

$$
-\frac{d C}{d t}=k C^{n}
$$

$C$ - is the concentration of PAH (mg/l), $t$ the time (days), $k$ the rate constant for chemical disappearance of PAH $\left(\right.$ days $\left.^{-1}\right)$ and $n$, the reaction order, which is unity for first order kinetics $[24,41]$. Based on the assumptions that only dissolved forms are available for biodegradation 
and that the biodegradation rate follows a first order kinetics [42], the logarithm of the ratio of residual PAH concentration to its initial (i.e., logarithm of $C / C_{0}$ ) can be plotted as a function of time and hence, the biodegradation rate being the gradient of the plot, can be determined.

\subsection{Michaelis-Menten kinetic model}

The most commonly assumed relationship for the assessment of bioremediation is done using the biodegradation rate and the concentration $(C)$ of the contaminants in the aqueous phase using the Michaelis-Menten kinetic model or Monod equation:

$$
V=\frac{\left(V_{\max } S\right)}{\left(K_{m}+S\right)}
$$

where $V$ is the biodegradation rate, $V_{\max }$ the maximum biodegradation rate, $K_{m}$ the MichaelisMenten constant, and $S$ the residual contaminant concentration. As depicted in Figure 2, at high $S, V$ becomes independent of $S$ and at low $S$, the equation is approximated to first order kinetics, i.e., $V$ is directly proportional to $S$. At all values of $S, V$ is always proportional to the biocatalyst concentration available for the biodegradation process.

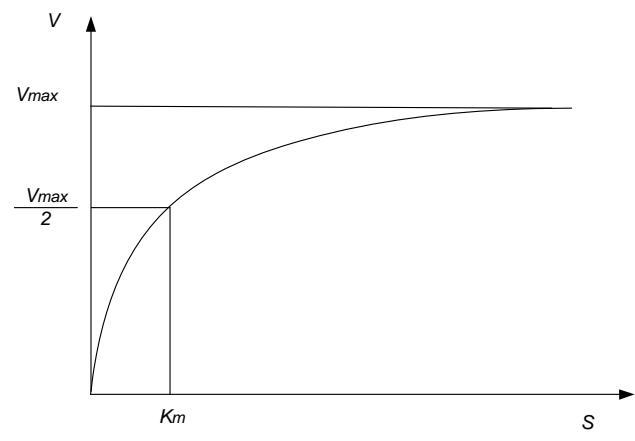

Figure 2. Michaelis-Menten kinetics rate profiles.

At low PAH concentrations, such as when the concentration of the contaminant is in the part per billion ranges usually encountered for underground water contaminations, insufficient energy and carbon source availability can become a limiting factor for microbial growth and maintenance. That is, a threshold may exist below which microbial biomass growth cannot be sustained. Such a minimum concentration for sustainable growth is defined as the concentration at which microbial growth is balanced by decay $[36,43]$. Also at such a concentration, the biodegradation rate reverts back to that described by first-order kinetics. However, the application of suitable microorganisms and/or their products can be used to enhance the concentration of $\mathrm{PAH}$ in the aqueous phase through increasing the desorption rate and mobilization from the sorbed phase. At such an enhanced concentration, Michaelis-Menten rate kinetics becomes appreciably applicable and from its linearized plot (Figure 3), the maximum PAH deg- 
radation rate can easily be determined. The rate equations can also be simplified by making certain assumptions. Particularly, the steady-state approximation which assumes a negligible change in the concentration of the enzyme-substrate complex during the course of the reaction. Furthermore, the Michaelis-Menten reaction mechanism presupposes that catalysis is irreversible and that the enzyme is not subject to any product inhibition. This limits the suitability of using this model to predict biodegradation rates where chemical surfactants have been known to inhibit product formation [44].

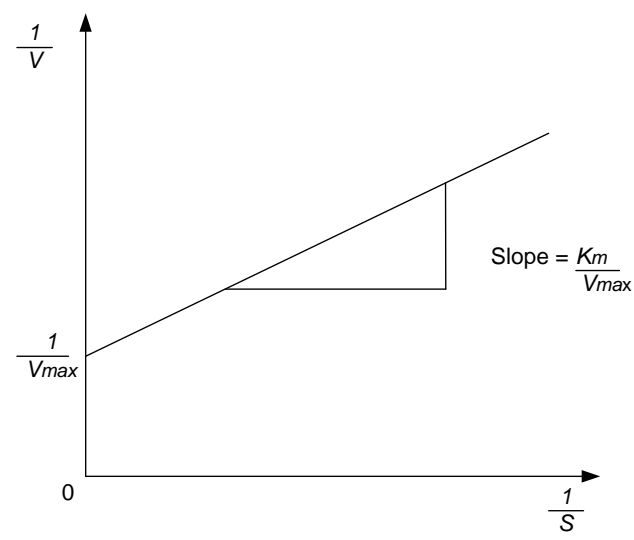

Figure 3. A plot of the linearized form of Michaelis-Menten rate equation.

\subsection{Freundlich adsorption isotherm}

The Freundlich isotherm is an adsorption isotherm which relates the concentration of a solute on the surface of an adsorbent to the concentration of the solute in the liquid with which it is in contact. The isotherm is mathematically represented as:

$$
Q=\frac{x}{m} k C^{\frac{1}{n}}
$$

For which the linearized form is:

$$
\log Q=\log k+N \log C \quad\left[N=\frac{1}{n}\right]
$$

where $Q$ is the sorbed amount of PAH (mg/g soil), $x$ the mass of PAH (mg), $m$ the mass of soil (g), $C$ the equilibrium concentration of PAH in solution $(\mathrm{mg} / \mathrm{l}), k$ and $n$ are constants for a given PAH and adsorbent, which can be either a solid or a liquid, at a particular temperature and thus define the isotherm's curvature. The amount of the sorbed PAH can be determined by plotting the isotherms' linearized form as a function of the equilibrium concentration of the PAH in solution (Figure 4). 


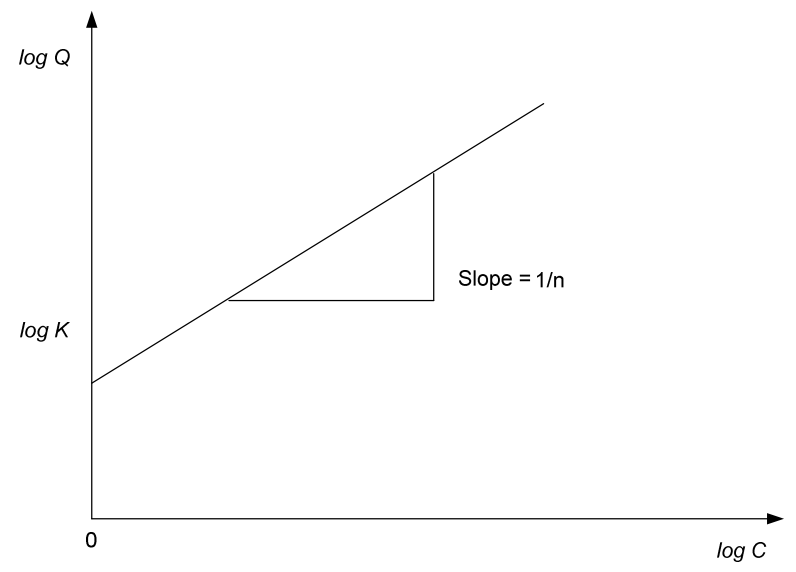

Figure 4. A plot of the linearized form of the Freundlich isotherm.

The isotherm can also be represented in terms of sorbent pore pressure $P$ as:

$$
Q=k P^{\frac{1}{n}}
$$

At high pressure, the extent of adsorption is independent of pressure (i.e. $1 / \mathrm{n}=0$ ), at low pressure, it is dependent on pressure.

In a recent study of biodegradation of phenanthrene and pyrene in a slurry soil system using Phanerochaete chrysosporium, biosorption isotherms were found to fit well with the Freundlich isotherm. The Freundlich $n$ values were approximated to unity, indicating that the biosorption was dominated by partitioning onto fungal biomass and the soils' organic matter [45, 46]. It also showed that the amount of PAH sorption by the microbial biomass was dependent on the concentration of the PAH present in the contaminated medium. The extent of adsorption varied directly with pressure until saturation pressure is reached. Beyond that point, the rate of adsorption reaches a maximum, even after applying higher pressure [47], thus the Freundlich adsorption isotherm will not be suitable at a higher pressure. Although, Langenfeld et al. [48] has shown that pressure variation has no effect on the supercritical extraction efficiency of PAHs, the use of Freundlich isotherm in biodegradation studies without considering the effects of pore pressure on sorption of HMW PAHs [45] can be problematic.

\subsection{Enhanced bioavailability model}

Zhang et al. [36] proposed a bioavailability model that can be used to quantitatively estimate the impact of sorption on the biodegradation by taking a mass balance for organic compounds in a batch system containing liquid and solids and substituting the expression into the Michaelis-Menten rate equation. The model assumed that only the organic contaminant in the liquid phase is biodegradable. Park et al. [49] extended the model us- 
ing formulations for reversible and instantaneous sorption-desorption processes with first-order biodegradation reactions in both liquid and solid phases, including the assumption that the liquid-phase degradation rate coefficient is not affected by the presence of solids. Under the sorption-desorption equilibrium assumption, the liquid-phase contaminant disappearance rate can be expressed as:

$$
\frac{d C}{d t}=E_{f} B_{f} k_{1} C
$$

Using integration, the concentration of PAHs in the aqueous phase at any particular time during the biodegradation process can be determined as:

$$
C=C_{0} \exp \left(E_{f} B_{f} k_{1} t\right)
$$

where, $E_{f}$ is the enhanced transformation factor (dimensionless);

$$
E_{f}=1+R_{s l} K_{d} f_{s} k_{s} / k_{1}
$$

$B_{f}$ is the bioavailability factor;

$$
B_{f}=1 /\left(1+R_{s l} K_{d}\right)
$$

$R_{s l}$ is solid/liquid ratio (mg/l);

$$
R_{s l}=m / V_{1}
$$

where $C$ is the liquid-phase concentration of contaminant $(\mathrm{mg} / \mathrm{l}), C_{0}$ the initial liquidphase concentration $(\mathrm{mg} / \mathrm{l}), t$ time $(\mathrm{min}), k_{1}$ the first-order liquid-phase degradation rate coefficient $\left(\mathrm{min}^{-1}\right)$ which can be determined from biodegradation assay, $K_{d}$ the sorption distribution coefficient (dimensionless), $f_{s}$ the fraction of attached biomass in the system (dimensionless), $k_{s}$ the first-order sorbed-phase degradation rate $\left(\mathrm{min}^{-1}\right), m$ the sorbent mass $(g)$, and $V_{l}$ is the liquid volume $(l)$.

The bioavailability factor $\left(B_{f}\right)$ range from the above equation is between zero and unity. A $B_{f}$ approaching unity indicates that the effect of sorption is practically negligible while a $B_{f}$ tending towards zero shows that biodegradation will be significantly limited by sorption [36]. On the other hand, if there is no sorbed-phase degradation by the attached biomass, $E_{f}$ is unity and the enhanced bioavailability model reduces to bioavailability model which assumes sorption-desorption and only liquid-phase biodegradation. An $E_{f}>1$ indicates that biodegradation is faster than that expected based on the liquid-phase degradation while $E_{f}<1$ indicates slower rates [49]. 


\subsection{Effects of temperature on bioavailability}

Studies have demonstrated that temperature optimization had a positive effect on biodegradation of hydrophobic organic compounds especially for PAHs in a soil historically contaminated with these hydrocarbons. These findings indicated that in-situ remediation processes are accelerated with elevated temperature in a range between mesophilic and thermophilic temperatures. However, at a high temperature, the activity of fungal and bacterial populations is reduced [50]. Temperatures in the thermophilic range $\left(50\right.$ to $60^{\circ} \mathrm{C}$ ) are shown to greatly accelerate decomposition of organic matter, in general [51]. Microbial utilization of hydrocarbons can occur at temperatures ranging from -2 to $70^{\circ} \mathrm{C}$. Iqbal et al. [52] investigated the ability of indigenous aerobic microorganisms to degrade low and HMW PAHs in sewage sludge fed in continuous bioreactors. It was reported that when the temperature increased from 35 to $45^{\circ} \mathrm{C}$ and at $55^{\circ} \mathrm{C}$, biodegradation of the high molecular weight PAHs was enhanced from 50 to $80 \%$. The results also showed improved kinetic rates with elevated temperature. A reduction in kinetic rates was associated with a decrease in contaminant concentrations over time; however, the kinetic rates were found to be dependent upon the contaminants desorption and environmental factors than concentration; i.e. significant kinetic rates was observed in the ambient and high temperature biodegradation processes.

Temperature elevation coupled with moisture optimization was also determined to enhance the bioremediation of such contaminated soil. Raising the temperature also decreases adsorption, which makes more organic material available for microorganisms to degrade. With the synergistic effects of elevated temperature and sufficient moisture content, White et al. [53] determined that moisture and slurrying soil containing organic compounds dramatically enhanced bioavailability and the rate of biodegradation. Reports also show that desorption resistant HMW PAHs were more efficiently metabolized in slurried than in unslurried soil suggesting that temperature and moisture optimization needs to be combined with efficient nutrient delivery systems for soils/sediments.

Furthermore, temperature plays a role when nutrients are added for biodegradation. Previous studies indicate that at $10^{\circ} \mathrm{C}$, biodegradation rates were not affected by the addition of phosphorus or nitrogen. However, at $20^{\circ} \mathrm{C}$, biodegradation was increased by the addition of phosphorus [54]. This suggests that temperature optimization needs to be combined with sufficient and suitable nutrient amendments. Sartoros et al. [55] considered the biodegradation of a mixture of two PAH compounds, pyrene and anthracene, by a developed enrichment culture with the addition of surfactant at a low temperature of $10^{\circ} \mathrm{C}$ and discovered a negative impact on the biodegradation. It was also observed that the overall extent and the maximum specific rate of PAHs mineralization decreased with the decrease of temperature; the variation of total PAH concentration had negligible effect. However, at $25^{\circ} \mathrm{C}$ the addition of a surfactant enhanced the mineralization of PAHs. These results have important implications on the use of surfactants for in-situ bioremediation since groundwater temperatures are often at or below $10^{\circ} \mathrm{C}$.

In a bioaugmentation system, where allochthonous or genetically engineered microorganisms are added into contaminated soil to aid the operation of indigenous microbes, microbial population can decline rapidly following their introduction into such natural soil, and growth 
of the engineered populations in microbiologically undisturbed soils is a rare phenomenon due to microbiostasis [56,57]. Furthermore, temperature variability is one of the principal contributors leading to the decline of microorganisms introduced into a 'hostile' soil microenvironment. In high temperature treatments, the response and survival of the microorganisms will be compromised compared to ambient temperature treatments. The microbial concentration increases under ambient temperature thus significantly increasing remediation activity. Results suggest that the stimulated growth and activity of indigenous microbes with elevated temperature in non-inoculated treatment indicates a positive relationship between optimum temperatures and better biodegradation performance.

\section{Enhancing bioavailability of HMW PAHs using biosurfactants from renewable resources}

\subsection{Effects of biosurfactants on sorbed PAHs}

Biosurfactants are surface active agents produced by microorganisms. Table 1 shows some of these microorganisms and the different groups of biosurfactant they produce. All biosurfactants consist of two parts, a polar (hydrophilic) moiety and a non polar (hydrophobic) group. A hydrophilic group consists of mono-, oligo- or polysaccharides, peptides or proteins and a hydrophobic moiety usually contains saturated, unsaturated and hydroxylated fatty acids or fatty alcohols [58]. Due to their amphiphilic structure, biosurfactants show a wide range of properties, including the lowering of surface and interfacial tension of liquids, the ability to form micelles and micro-emulsions between two different phases, the ability to increase the surface area of hydrophobic water-insoluble substances, and thus increase the water bioavailability of such substances. In comparison to their chemically synthesized equivalents they have many advantages; they are environmentally friendly, biodegradable, less toxic and nonhazardous. They have better foaming properties and higher selectivity; they are active at extreme temperatures, $\mathrm{pH}$ and salinity, and can be produced from wastes and from various by-products. This feature makes the production of cheap biosurfactants possible and the concomitant effects of utilizing waste substrates and reducing their environmental pollution [59-63]. Biosurfactants increase the bioavailability of PAHs resulting in enhanced growth of the degrading microorganism and the biodegradation of the contaminants.

An important feature of the physico-chemical properties of surfactants is their hydrophiliclipophilic balance (HLB) [64, 65]. The HLB value indicates whether a surfactant will produce a water-in-oil or oil-in-water emulsion. Emulsifiers with lower HLB values of 3 to 6 are lipophilic and promote water-in-oil emulsification, while emulsifiers with higher HLB values between 10 and 18 are more hydrophilic and promote oil-in-water emulsion formation [5]. A classification based on HLB values has been used to evaluate the suitability of different surfactants for various applications. For example, it has been reported that successful surfactants are those with the ability to promote desorption of contaminants from contaminated soils and are normally those with HLB values above 10 [66]. 


\begin{tabular}{|c|c|c|c|c|}
\hline \multicolumn{2}{|c|}{ Biosurfactant } & \multirow[t]{2}{*}{ Microorganism } & \multirow[t]{2}{*}{ Applications in Environmental Biotechnology } & \multirow{2}{*}{$\begin{array}{c}\text { Reference } \\
\text { s }\end{array}$} \\
\hline Group & Class & & & \\
\hline \multirow[t]{3}{*}{ Glycolipids } & Rhamnolipids & $\begin{array}{l}\text { Pseudomonas aerugi- } \\
\text { nosa, Pseudomonas sp }\end{array}$ & $\begin{array}{l}\text { Enhancement of the degradation, dispersion, emulsifi- } \\
\text { cation of different classes of hydrocarbons and vegeta- } \\
\text { ble oils; removal of metals from soil. }\end{array}$ & {$[69,71]$} \\
\hline & Trehalolipids & $\begin{array}{l}\text { Mycobacterium tuber- } \\
\text { culosis, Rhodococcus er- } \\
\text { ythropolis, Arthrobacter } \\
\text { sp., Nocardia sp., Cory- } \\
\text { nebacterium sp. }\end{array}$ & Enhancement of the bioavailability of hydrocarbons. & [72] \\
\hline & Sophorolipids & $\begin{array}{l}\text { Torulopsis bombicola, } \\
\text { Torulopsis petrophilum, } \\
\text { Torulopsis apicola }\end{array}$ & $\begin{array}{l}\text { Recovery of hydrocarbons from dregs and muds; re- } \\
\text { moval of heavy metals from sediments; enhancement } \\
\text { of oil recovery. }\end{array}$ & {$[73,74,69]$} \\
\hline \multirow{3}{*}{$\begin{array}{l}\text { Fatty acids, } \\
\text { phospholipids } \\
\text { and neutral } \\
\text { lipids }\end{array}$} & $\begin{array}{l}\text { Corynomycolic } \\
\text { acid }\end{array}$ & Corynebacterium lepus & Enhancement of bitumen recovery. & [75] \\
\hline & Spiculisporic acid & $\begin{array}{l}\text { Penicillium spiculispo- } \\
\text { rum }\end{array}$ & $\begin{array}{l}\text { Removal of metal ions from aqueous solution; disper- } \\
\text { sion action for hydrophilic pigments; preparation of } \\
\text { emulsion-type organogels, microencapsulation }\end{array}$ & {$[76]$} \\
\hline & $\begin{array}{l}\text { Phosphati-dyle- } \\
\text { thanolamine }\end{array}$ & $\begin{array}{l}\text { Acinetobacter sp., Rho- } \\
\text { dococcus erythropolis }\end{array}$ & Increasing the tolerance of bacteria to heavy metals. & [77] \\
\hline \multirow[t]{2}{*}{ Lipopeptides } & Surfactin & Bacillus subtilis & $\begin{array}{l}\text { Enhancement of the biodegradation of hydrocarbons } \\
\text { and chlorinated pesticides; removal of heavy metals } \\
\text { from a contaminated soil, sediment and water; increas- } \\
\text { ing the effectiveness of phytoextraction. }\end{array}$ & [78] \\
\hline & Lichenysin & Bacillus licheniformis & Enhancement of oil recovery & [79] \\
\hline \multirow[t]{5}{*}{$\begin{array}{l}\text { Polymeric bio- } \\
\text { surfactants }\end{array}$} & Emulsan & $\begin{array}{c}\text { Acinetobacter calcoace- } \\
\text { ticus RAG-1 }\end{array}$ & Stabilization of the hydrocarbon-in-water emulsions. & {$[80]$} \\
\hline & Alasan & $\begin{array}{c}\text { Acinetobacter radiore- } \\
\text { sistens KA-53 }\end{array}$ & & [81] \\
\hline & Biodispersan & $\begin{array}{c}\text { Acinetobacter calcoace- } \\
\text { ticus A2 }\end{array}$ & Dispersion of limestone in water. & [82] \\
\hline & Liposan & Candida lipolytica & Stabilization of hydrocarbon-in-water emulsions. & [83] \\
\hline & Mannoprotein & $\begin{array}{c}\text { Saccharomyces cerevi- } \\
\text { siae }\end{array}$ & & [84] \\
\hline
\end{tabular}

Source: Pacwa-Płociniczak et al. [85]

Table 1. Biosurfactants producing organisms: classification and application in environmental biotechnology. 
Another feature is the Critical Micelle Concentration (CMC); which is the concentration above which the formation of micelles is thermodynamically favored [67]. The mobilization mechanism occurs at concentrations below the biosurfactant CMC. At such concentrations, biosurfactants reduce the surface and interfacial tension between air-water and soil-water systems. Due to the reduction of the interfacial force, contact of biosurfactants with a soil-oil system increases the contact angle and reduces the capillary force holding the oil and soil together. Above the biosurfactant $\mathrm{CMC}$, the solubilization process takes place. At these concentrations, biosurfactant molecules aggregate to form micelles, which dramatically increase the solubility of the oil. The hydrophobic part of the biosurfactant molecules interconnect inside the micelle while the hydrophilic ends are then exposed to the aqueous phase on the exterior. Consequently, the interior of a micelle creates an environment compatible for hydrophobic organic molecules. The process of incorporation of these molecules into a micelle is known as solubilization [68]. The formation of micelles leads to a significant increase in the apparent solubility of hydrophobic organic compounds, even above their water solubility limit, as these compounds can partition into the central core of a micelle. The effects of such a process are the reduction of surface and interfacial tension, enhancement of mobilization and mass transfer of contaminants from soil particles into the aqueous phase, and consequently the bioavailability of the hydrophobic contaminants for microbial attack $[69,70]$.

\subsection{Biosurfactants production using agricultural and industrial wastes}

The bioconversion of waste materials is considered to be of importance for the development of sustainable biotechnology processes in the near future because of its favorable economics, low capital and energy cost, reduction in environmental pollution, and their relative ease of operation $[86,10,87,88]$. Producing usable products from agricultural and industrial waste is therefore a feasible and favorable option $[89,90]$. Modern society produces high quantity of waste materials through activities related to industries such as those in the forestry, agriculture and municipal sectors $[86,91]$.

The use of the alternative substrates such as agro-based industrial wastes is one of the attractive strategies for the economic production of biosurfactants to enhance biodegradation of environmental hydrophobic contaminants. It has been suggested that successful approaches to more economical production technologies of biosurfactants will be a collaborative approach involving process development and sustainable raw material supplies. According to Marchant and Banat [92], emphasis should be on the cost effective management of downstream processing. These inexpensive agro-industrial wastes substrates include olive oil mill effluent, plant oil extracts and waste, distillery and whey wastes, potato process effluent and cassava wastewater [10]. These waste materials are some examples of food industry by-products or waste that can be used as feedstock for biosurfactants production. Similarly, vegetable oil wastes can be used for biosurfactant production as they are lipidic carbon sources and are mostly comprised of saturated or unsaturated fatty acids with 16 to18 carbon atoms chain.

Studies involving the application of a variety of vegetable oils for biosurfactants production from canola, corn, sunflower, safflower, olive, rapeseed, grape seed, palm, coconut, fish and soybean oil have been reported. The world production of oils and fats is about 2.5 to 3 million 
tons, $75 \%$ of which are derived from plants and oil seeds [93]. The high content of fats, oils and other nutrients in these wastes make them invaluable cheap raw materials for industries involved in useful metabolite production. Furthermore, from an economical point of view, nutrient rich agricultural residues can be employed for producing useful biological products such as biosurfactants. These materials are among the most abundant organic carbon available on earth [94] and they are the major components of different waste streams from various industries.

In recent times, studies have been focused on the application of agro-industrial wastes or byproducts for the production of biosurfactants which are used in crude form or the direct use of surfactants producing strains for biodegradation processes. This is due to the high cost of biosurfactant purification and the stability including sustainability provided by these biosurfactants producing strains in biodegradation processes. The production and properties of a biosurfactant, synthesized by Bacillus subtilis LB5a strain, using cassava wastewater as a substrate was investigated. The microorganism was able to grow and to produce a surfactant on cassava waste, reducing the surface tension of the medium to $26.6 \mathrm{mN} / \mathrm{m}$ and giving a crude surfactant concentration of $3.0 \mathrm{~g} / \mathrm{L}$ after $48 \mathrm{~h}$ [95]. The biosurfactant obtained was capable of forming stable emulsions with various hydrocarbons. Panesar et al. [96] investigated the suitability of molasses, the sugar industry by-product, for biosurfactant production using Pseudomonas aeruginosa strain ATCC 2297. An attempt was also made to replace the costly nitrogen sources with agro-industrial by-products to formulate low cost medium for biosurfactants production. The strain was found to displayed maximum emulsification activity on molasses medium after $120 \mathrm{~h}$ of incubation under optimized conditions. Biosurfactants production by a strain of Pseudomonas aeruginosa using palm oil as a sole carbon source was also investigated [97]. The $P$. aeruginosa strain gave emulsification index results of $100 \%$ when diesel was used as an oil phase and was able to reduce surface tension of three tested inorganic media to approximately $33 \mathrm{mN} / \mathrm{m}$. Wan-Nawawi et al. [98] also reported the versatility of a bacterial strain isolated from a hydrocarbon-based source at a palm oil mill. The strain showed a high bacterial growth on sludge palm oil with a surface tension of $36.2 \mathrm{mN} / \mathrm{m}$ and was therefore proposed for biosurfactant production by liquid state fermentation.

\subsection{Application of biosurfactants for enhancing PAHs bioavailability}

Only limited numbers of microorganisms are capable of degrading HMW PAHs. Hence their biodegradation is limited by their low bioavailability to the microorganisms, which is due to their hydrophobicity, low aqueous solubility and strong adsorptive capacity in soil [99, 100]. Berg et al. [101] described an emulsifying agent produced by P. aeruginosa UG2 that increased the solubility of hexachlorobiphenyl added to soil slurries, resulting in a $31 \%$ recovery of the compound in the aqueous phase. Griffin et al. [102] demonstrated that rhamnolipids from bacteria, in combination with the oleophilic fertilizer Inipol EAp-22, increased the degradation rate of hexadecane, benzene, toluene, $\mathrm{o}-$ and p-cresol and naphthalene in aqueous-phase bioreactors and in those containing soil. They also reported increased rates of biodegradation of aliphatic and aromatic hydrocarbons by pure bacterial cultures. 
The efficiency of biosurfactants in the remediation of soil contaminated by phenanthrene and polychlorinated biphenyls (PCBs) was also reported [103]. In an investigation of the capacity of PAH-utilizing bacteria to produce biosurfactants using naphthalene and phenanthrene, Deziel et al. [104] quantified biosurfactants production that was responsible for an increase in the aqueous concentration of naphthalene. This indicates a potential role for biosurfactants in increasing the solubility of such compounds. Similarly, Zhang et al. [105] determined the effect of two biosurfactants on the dissolution and bioavailability of phenanthrene and reported increases in both solubility and the degradation rate of phenanthrene. Kanga et al. [106] applied glycolipid biosurfactants produced by Rhodococcus sp. H13A and a synthetic surfactant (Tween 80) for enhanced substrate solubility. Using naphthalene and methyl-substituted derivatives in crude oil as representative of the PAH content, they observed that both surfactants lowered surface tension in solutions from 72 to $30 \mathrm{mN} / \mathrm{m}$. The biosurfactants were efficient in increasing the solubility of the hydrocarbons, particularly the substituted derivative. In a laboratory column study, Noordman et al. [107] applied biosurfactants for the enhanced removal of phenanthrene from phenanthrene-contaminated soil, eluting the contaminant with an electrolyte solution containing rhamnolipid. The enhanced removal of phenanthrene occurred mainly by micellar solubilization.

Microbially produced biosurfactants were studied to enhance crude oil desorption and mobilization in model soil column systems [108]. The results showed that the ability of biosurfactants from Rhodococcus ruber to remove the oil from the soil core was 1.4 to 2.3 times greater than that of a synthetic surfactant (Tween 60), of suitable properties. The biosurfactant was less adsorbed to soil components than synthetic surfactant, thus rapidly penetrating through the soil column and effectively removing $65-82 \%$ of the crude oil. Chemical analysis showed that the crude oil removed by the biosurfactant contained a lower proportion of highmolecular-weight paraffins and asphaltenes.

The capability of biosurfactants and biosurfactant-producing microorganisms to enhance organic contaminants' availability and biodegradation rates was reported by several authors [109, 110, 104]. Kang et al. [111] used sophorolipid in studies on biodegradation of aliphatic and aromatic hydrocarbons and Iranian light crude oil under laboratory conditions. The addition of this biosurfactant to soil increased biodegradation of tested hydrocarbons with the rate of degradation ranging from $85 \%$ to $97 \%$ of the total amount of hydrocarbons. Their results indicated that sophorolipid may have the potential for facilitating the bioremediation of sites contaminated with hydrocarbons having limited water solubility and increasing the viability of microbial consortia for biodegradation. The solubility and utilization of pyrene as a sole carbon source by the biosurfactant-producing bacterial strains; Bacillus subtilis DM-04, Pseudomonas aeruginosa mucoid (M) and nonmucoid (NM), isolated from a petroleum-contaminated soil were studied [112]. It was reported that the biosurfactants produced by the bacteria under the study were capable of enhancing the solubility of pyrene in aqueous media and can influence the cell surface hydrophobicity of the biosurfactant-producing strains that results in a higher uptake of pyrene. 


\section{Conclusion}

Although environmental biotechnology is regarded as an eco-friendly technology for the clean-up of PAH-contaminated ecosystems, the successful application of this technology is still restricted by the enormous costs of its operation and the limited bioavailability of the contaminants to degradative micro-organisms, especially HMW PAHs, due to sorption and sequestration. Many bacteria, fungi and algae and their products have been applied to degrade a range of LMW PAHs, such as naphthalene, fluorene and phenanthrene; however, their activity towards HMW PAHs containing five or more fused benzene rings, such as Benzo(a)pyrene and Benzo(ghi)perylene, is limited. Application of biosurfactants produced using agricultural and industrial wastes may be promising for reducing the costs of biodegradation technology as well as enhancing bioavailability of HMW PAHs. However, there is a dearth of research on this subject. Bioavailability model could be a vital tool to estimate and assess the success of bioremediation; therefore, more research is needed in this area, considering variations in environmental conditions that could limit field simulation of laboratory results. The synergistic effects of increased temperature and moisture with biosurfactants application have been shown to enhance biodegradation efficiency; however, kinetic investigation is important under these conditions to provide an understanding of biodegradation rate in situation where these conditions cannot be controlled such as in a typical field operation.

\section{Author details}

Olusola Solomon Amodu ${ }^{1}$, Tunde Victor Ojumu ${ }^{1}$ and Seteno Karabo Obed Ntwampe ${ }^{2}$

1 Faculty of Engineering, Department of Chemical Engineering, Cape Peninsula University of Technology, Cape Town, South Africa

2 Faculty of Applied Sciences, Department of Agriculture and Food Sciences: Biotechnology Programme, Cape Peninsula University of Technology, Cape Town, South Africa

\section{References}

[1] USEPA U. Integrated Risk Information System (IRIS). EPA; 1999.

[2] Acevedo F, Pizzul L, Castillo MP, Cuevas R, Diez MC. Degradation of polycyclic aromatic hydrocarbons by the Chilean white-rot fungus Anthracophyllum discolor. Journal of Hazardous Materials. 2011;185(1):212-9.

[3] Acevedo F, Pizzul L, González M, Cea M, Gianfreda L, Diez M. Degradation of polycyclic aromatic hydrocarbons by free and nanoclay-immobilized manganese peroxidase from Anthracophyllum discolor. Chemosphere. 2010;80(3):271-8. 
[4] Fernando Bautista L, Morales G, Sanz R. Immobilization strategies for laccase from Trametes versicolor on mesostructured silica materials and the application to the degradation of naphthalene. Bioresource Technology. 2010;101(22):8541-8.

[5] Nilanjana D, Preethy C. Microbial degradation of petroleum hydrocarbon contaminants: An overview. Biotechnology Research International. 2010;2011.

[6] Cameotra SS, Singh P. Bioremediation of oil sludge using crude biosurfactants. International Biodeterioration and Biodegradation. 2008;62(3):274-80.

[7] Mancera-Lopez M, Esparza-Garcia F, Chavez-Gomez B, Rodriguez-Vazquez R, Saucedo-Castaneda G, Barrera-Cortes J. Bioremediation of an aged hydrocarboncontaminated soil by a combined system of biostimulation-bioaugmentation with filamentous fungi. International Biodeterioration and Biodegradation. 2008;61(2): 151-60.

[8] Henkel M, Müller MM, Kügler JH, Lovaglio RB, Contiero J, Syldatk C, et al. Rhamnolipids as biosurfactants from renewable resources: Concepts for next-generation rhamnolipid production. Process Biochemistry. 2012.

[9] Rubilar O, Tortella G, Cea M, Acevedo F, Bustamante M, Gianfreda L, et al. Bioremediation of a Chilean Andisol contaminated with pentachlorophenol (PCP) by solid substrate cultures of white-rot fungi. Biodegradation. 2011;22(1):31-41.

[10] Makkar RS, Cameotra SS, Banat IM. Advances in utilization of renewable substrates for biosurfactant production. AMB Express. 2011;1(1):1-19.

[11] Rodríguez-Meza MA, Chávez-Gómez B, Poggi-Varaldo HM, Ríos-Leal E, BarreraCortés J. Design of a new rotating drum bioreactor operated at atmospheric pressure on the bioremediation of a polluted soil. Bioprocess and Biosystems Engineering. 2010;33(5):573-82.

[12] Stokes JD, Paton G, Semple KT. Behaviour and assessment of bioavailability of organic contaminants in soil: relevance for risk assessment and remediation. Soil Use and Management. 2005;21:475-86.

[13] ECETOC. European Centre for Ecotoxicology and Toxicology of Chemicals. Scientific principles of soil hazard assessment of substances: a technical report. 2002(84):24-6.

[14] USNRC. Bioavailability of contaminants in soils and sediments: processes, tools and applications. National Academic Press: Washington, DC. 2002.

[15] Van Leeuwen CJH, J. L. M.. Terrestrial toxicity. In Risk Assessment of Chemicals: an introduction. Kluwer Academic, Dordrecht, The Netherlands. . 1995: 211-6.

[16] Herrchen M. Bioavailability as a Key Property in Terrestrial Ecotoxicity Assessment and Evaluation: Major Statements and Abstracts of Presentations of an International European Workshop: Held at the Fraunhofer-Institute for Environmental Chemistry and Ecotoxicology IUCT Schmallenberg, Germany, April 22-23, 1996: Fraunhofer-IRBVerl.; 1997. 
[17] Klaassen CD, Admur MO. Casarett and Doull's toxicology: the basic science of poisons. 2001.

[18] Semple KT, Morriss A, Paton G. Bioavailability of hydrophobic organic contaminants in soils: fundamental concepts and techniques for analysis. European Journal of Soil Science. 2003;54(4):809-18.

[19] Alexander M. Aging, bioavailability, and overestimation of risk from environmental pollutants. Environmental Science and Technology. 2000;34(20):4259-65.

[20] Ruby MV, Davis A, Schoof R, Eberle S, Sellstone CM. Estimation of lead and arsenic bioavailability using a physiologically based extraction test. Environmental Science and Technology. 1996;30(2):422-30.

[21] Kramer BK, Ryan PB. Soxhlet and microwave extraction in determining the bioaccessibility of pesticides from soil and model solids. Proceedings of the 2000 Conference on Hazardous Waste Research 2000:pp 196-210.

[22] Khan MI, Cheema SA, Shen C, Zhang C, Tang X, Shi J, et al. Assessment of phenanthrene bioavailability in aged and unaged soils by mild extraction. Environmental Monitoring and Assessment. 2011.

[23] Harmsen J. Measuring bioavailability: From a scientific approach to standard methods. Journal of Environmental Quality. 2007;36(5):1420-8.

[24] Alexander M. Biodegradation and Bioremediation, Academic Press, Inc., San Diego, CA. 1999.

[25] Uyttebroek M, Spoden A, Ortega-Calvo JJ, Wouters K, Wattiau P, Bastiaens L, et al. Differential Responses of Eubacterial, Mycobacterium, and Sphingomonas Communities in Polycyclic Aromatic Hydrocarbon(PAH)-Contaminated Soil to Artificially Induced Changes in PAH Profile. Journal of Environmental Quality. 2007;36(5):1403-11.

[26] Bergknut M. Characterization of PAH-contaminated soils focusing on availability, chemical composition and biological effects. Disertation at Umeå University. 2006.

[27] Bosma TNP, Middeldorp PJM, Schraa G, Zehnder AJB. Mass transfer limitation of biotransformation: quantifying bioavailability. Environmental Science and Technology. 1996;31(1):248-52.

[28] Burgos WD, Novak JT, Berry DF. Reversible sorption and irreversible binding of naphthalene and $\alpha$-naphthol to soil: Elucidation of processes. Environmental Science and Technology. 1996;30(4):1205-11.

[29] Luthy RG, Aiken GR, Brusseau ML, Cunningham SD, Gschwend PM, Pignatello JJ, et al. Sequestration of hydrophobic organic contaminants by geosorbents. Environmental Science and Technology. 1997;31(12):3341-7.

[30] McNally DL, Mihelcic JR, Stapleton JM. Bioremediation for soil reclamation. 2007. 
[31] Wu SC, Gschwend PM. Sorption kinetics of hydrophobic organic compounds to natural sediments and soils. Environmental Science and Technology. 1986;20(7):717-25.

[32] Nam K, Chung N, Alexander M. Relationship between organic matter content of soil and the sequestration of phenanthrene. Environmental Science and Technology. 1998;32(23):3785-8.

[33] Hundal LS, Thompson ML, Laird DA, Carmo AM. Sorption of phenanthrene by reference smectites. Environmental Science and Technology. 2001;35(17):3456-61.

[34] Yang Y, Zhang N, Xue M, Tao S. Impact of soil organic matter on the distribution of polycyclic aromatic hydrocarbons (PAHs) in soils. Environmental Pollution. 2010;158(6):2170-4.

[35] Reid BJ, Jones KC, Semple KT. Bioavailability of persistent organic pollutants in soils and sediments--a perspective on mechanisms, consequences and assessment. Environmental Pollution. 2000;108(1):103-12.

[36] Zhang W, Bouwer EJ, Ball WP. Bioavailability of Hydrophobic Organic Contaminants: Effects and Implications of Sorption Related Mass Transfer on Bioremediation. Ground Water Monitoring and Remediation. 1998;18(1):126-38.

[37] Johnsen AR, Wick LY, Harms H. Principles of microbial PAH-degradation in soil. Environmental Pollution. 2005;133(1):71-84.

[38] Ball W, Buehler C, Harmon T, Mackay D, Roberts P. Characterization of a sandy aquifer material at the grain scale. Journal of Contaminant Hydrology. 1990;5(3):253-95.

[39] Alexander M. Introduction to soil microbiology. Soil Science. 1978;125(5):331.

[40] Lawrence G, Payne D, Greenland D. Pore size distribution in critical point and freeze dried aggregates from clay subsoils. Journal of Soil Science. 1979;30(3):499-516.

[41] Kwon SH, Kim JH, Cho D. An analysis method for degradation kinetics of lowly concentrated PAH solutions under UV light and ultrasonication. Journal of Industrial and Engineering Chemistry. 2009;15(2):157-62.

[42] Yang Y, Shu L, Wang X, Xing B, Tao S. Effects of composition and domain arrangement of biopolymer components of soil organic matter on the bioavailability of phenanthrene. Environmental Science and Technology. 2010;44(9):3339-44.

[43] Rittmann BE, McCarty PL. Model of steady state biofilm kinetics. Biotechnology and Bioengineering. 1980;22(11):2343-57.

[44] Zhao Z, Wong JWC. Biosurfactants from Acinetobacter calcoaceticus BU03 enhance the solubility and biodegradation of phenanthrene. Environmental Tchnology. 2009;30(3): 291-9.

[45] Chen B, Ding J. Biosorption and biodegradation of phenanthrene and pyrene in sterilized and unsterilized soil slurry systems stimulated by Phanerochaete chrysosporium. Journal of hazardous materials. 2012. 
[46] Chen B, Wang Y, Hu D. Biosorption and biodegradation of polycyclic aromatic hydrocarbons in aqueous solutions by a consortium of white-rot fungi. Journal of Hazardous Materials. 2010;179(1):845-51.

[47] Levenspiel O. Chemical reactions engineering. Recherche. 1998;67:02.

[48] Langenfeld JJ, Hawthorne SB, Miller DJ, Pawliszyn J. Effects of temperature and pressure on supercritical fluid extraction efficiencies of polycyclic aromatic hydrocarbons and polychlorinated biphenyls. Analytical Chemistry. 1993;65(4):338-44.

[49] Park JH, Zhao X, Thomas C. Biodegradation of non-desorbable naphthalene in soils. Environmental Science and Technology. 2001;35(13):2734-40.

[50] Wise D, Torantolo D. Remediation engineering of hazardous waste contaminated soil. 1994. Marcel Dekker Inc., NY.

[51] Parr J, Sikora L, Burge W. Factors affecting the degradation and inactivation of waste constituents in soils. Land Treatment of Hazardous Wastes. 1983:20-49.

[52] Iqbal J, Metosh-Dickey C, Portier RJ. Temperature effects on bioremediation of PAHs and PCP contaminated south Louisiana soils: a laboratory mesocosm study. Journal of Soils and Sediments. 2007;7(3):153-8.

[53] White JC, Alexander M, Pignatello JJ. Enhancing the bioavailability of organic compounds sequestered in soil and aquifer solids. Environmental Toxicology and Chemistry. 1999;18(2):182-7.

[54] Walworth J, Reynolds C. Bioremediation of a petroleum-contaminated cryic soil: Effects of phosphorus, nitrogen, and temperature. Soil and Sediment Contamination. 1995;4(3):299-310.

[55] Sartoros C, Yerushalmi L, Béron P, Guiot SR. Effects of surfactant and temperature on biotransformation kinetics of anthracene and pyrene. Chemosphere. 2005;61(7): 1042-50.

[56] Ho W, Ko W. Soil microbiostasis: effects of environmental and edaphic factors. Soil Biology and Biochemistry. 1985;17(2):167-70.

[57] Van Veen J, Van Overbeek L, Van Elsas J. Fate and activity of microorganisms introduced into soil. Microbiology and Molecular Biology Reviews. 1997;61(2):121-35.

[58] Lang S. Biological amphiphiles (microbial biosurfactants). Current Opinion in Colloid and Interface Science. 2002;7(1-2):12-20.

[59] Kosaric N. Biosurfactants in industry. Pure and Applied Chemistry. 1992;64:1731-.

[60] Rahman K, Rahman TJ, Kourkoutas Y, Petsas I, Marchant R, Banat I. Enhanced bioremediation of alkane in petroleum sludge using bacterial consortium amended with rhamnolipid and micronutrients. Bioresource Technology. 2003;90(2):159-68.

[61] Kosaric N. Biosurfactants and their application for soil bioremediation. Food Technology and Biotechnology. 2001;39(4):295-304. 
[62] Das K, Mukherjee AK. Comparison of lipopeptide biosurfactants production by Bacillus subtilis strains in submerged and solid state fermentation systems using a cheap carbon source: Some industrial applications of biosurfactants. Process Biochemistry. 2007;42(8):1191-9.

[63] Das P, Mukherjee S, Sen R. Improved bioavailability and biodegradation of a model polyaromatic hydrocarbon by a biosurfactant producing bacterium of marine origin. Chemosphere. 2008;72(9):1229-34.

[64] González N, Simarro R, Molina M, Bautista L, Delgado L, Villa J. Effect of surfactants on PAH biodegradation by a bacterial consortium and on the dynamics of the bacterial community during the process. Bioresource Technology. 2011.

[65] Tiehm A. Degradation of polycyclic aromatic hydrocarbons in the presence of synthetic surfactants. Applied and Environmental Microbiology. 1994;60(1):258-63.

[66] Volkering F, Breure A, Rulkens W. Microbiological aspects of surfactant use for biological soil remediation. Biodegradation. 1997;8(6):401-17.

[67] Haigh SD. A review of the interaction of surfactants with organic contaminants in soil. Science of the Total Environment. 1996;185(1-3):161-70.

[68] Urum K, Pekdemir T. Evaluation of biosurfactants for crude oil contaminated soil washing. Chemosphere. 2004;57(9):1139-50.

[69] Whang LM, Liu PWG, Ma CC, Cheng SS. Application of biosurfactants, rhamnolipid, and surfactin, for enhanced biodegradation of diesel-contaminated water and soil. Journal of Hazardous Materials. 2008;151(1):155-63.

[70] Perfumo AS, T.J.P.; Marchant, R.;, Banat I. Production and Roles of Biosurfactants and Bioemulsifiers in Accessing Hydrophobic Substrates: In Handbook of Hydrocarbon and Lipid Microbiology ed Timmis, K.N. Chap. 47. 2010;Vol. 2(7):1501- 12. SpringerVerlag, Berlin.

[71] Sifour M, Al-Jilawi MH, Aziz GM. Emulsification properties of biosurfactant produced from Pseudomonas aeruginosa RB 28. Pakistan Journal of Biological Sciences: PJBS. 2007;10(8):1331.

[72] Franzetti A, Gandolfi I, Bestetti G, Smyth TJP, Banat IM. Production and applications of trehalose lipid biosurfactants. European Journal of Lipid Science and Technology. 2010;112(6):617-27.

[73] Baviere M, Degouy D, Lecourtier J. Process for washing solid particles comprising a sophoroside solution. Google Patents; 1994.

[74] Pesce L. A biotechnological method for the regeneration of hydrocarbons from dregs and muds, on the base of biosurfactants. WO Patent WO/2002/062,495; 2002.

[75] Gerson D, Zajic J. Surfactant production from hydrocarbons by Corynebacterium lepus, sp. nov. and Pseudomonas asphaltenicus, sp. nov. Development in Industrial Microbiology. 1978;19:577-99. 
[76] Hong JJ, Yang SM, Lee CH, Choi YK, Kajiuchi T. Ultrafiltration of divalent metal cations from aqueous solution using polycarboxylic acid type biosurfactant. Journal of Colloid and Interface Science. 1998;202(1):63-73.

[77] Appanna VD, Finn H, Pierre MS. Exocellular phosphatidylethanolamine production and multiple-metal tolerance in Pseudomonas fluorescens. FEMS Microbiology Letters. 1995;131(1):53-6.

[78] Awashti N, Kumar A, Makkar R, Cameotra S. Enhanced biodegradation of endosulfan, a chlorinated pesticide in presence of a biosurfactant. Journal of Environmental Science and Health B. 1999;34:793-803.

[79] Thomas C, Duvall M, Robertson E, Barrett K, Bala G. Surfactant-based EOR mediated by naturally occurring microorganisms. SPE Reservoir Engineering. 1993;8(4):285-91.

[80] Zosim Z, Gutnick D, Rosenberg E. Properties of hydrocarbon in water emulsions stabilized by Acinetobacter RAG1 emulsan. Biotechnology and Bioengineering. 1982;24(2):281-92.

[81] Toren A, Navon-Venezia S, Ron EZ, Rosenberg E. Emulsifying activities of purified Alasan proteins from Acinetobacter radioresistens KA53. Applied and Environmental Microbiology. 2001;67(3):1102-6.

[82] Rosenberg E, Rubinovitz C, Legmann R, Ron E. Purification and chemical properties of Acinetobacter calcoaceticus A2 biodispersan. Applied and Environmental Microbiology. 1988;54(2):323-6.

[83] Cirigliano MC, Carman GM. Purification and characterization of liposan, a bioemulsifier from Candida lipolytica. Applied and Environmental Microbiology. 1985;50(4): 846-50.

[84] Cameron DR, Cooper DG, Neufeld R. The mannoprotein of Saccharomyces cerevisiae is an effective bioemulsifier. Applied and Environmental Microbiology. 1988;54(6): 1420-5.

[85] Pacwa-Płociniczak M, Płaza GA, Piotrowska-Seget Z, Cameotra SS. Environmental applications of biosurfactants: Recent advances. International Journal of Molecular Sciences. 2011;12(1):633-54.

[86] Montoneri E, Savarino P, Bottigliengo S, Boffa V, Prevot AB, Fabbri D, et al., editors. Biomass wastes as renewable source of energy and chemicals for the industry with friendly environmental impact. 2009: Parlar Scientific Publications.

[87] Lopes FN. Industrial exploitation of renewable resources: from ethanol production to bioproducts development. Journal de la Société de Biologie. 2008;202(3):191.

[88] Deleu M, Paquot M. From renewable vegetables resources to microorganisms: new trends in surfactants. Comptes Rendus Chimie. 2004;7(6):641-6. 
[89] Makkar R, Cameotra S. An update on the use of unconventional substrates for biosurfactant production and their new applications. Applied Microbiology and Biotechnology. 2002;58(4):428-34.

[90] Moldes AB, Torrado AM, Barral MT, Domínguez JM. Evaluation of biosurfactant production from various agricultural residues by Lactobacillus pentosus. Journal of Agricultural and Food Chemistry. 2007;55(11):4481-6.

[91] Martins V, Kalil S, Bertolin T, Costa J. Solid state biosurfactant production in a fixedbed column bioreactor. Zeitschrift fur Naturfoschung. 2006;61(9/10):721.

[92] Marchant TJPSAPR, Banat I. Isolation and Analysis of Low Molecular Weight Microbial Glycolipids. 2010.

[93] Dumont MJ, Narine SS. Soapstock and deodorizer distillates from North American vegetable oils: Review on their characterization, extraction and utilization. Food Research International. 2007;40(8):957-74.

[94] Kukhar V. Biomass-Renewable Feedstock for Organic Chemicals ("White Chemistry"). Kemija u Industriji. 2009;58.

[95] Nitschke M, Pastore GM. Production and properties of a surfactant obtained from Bacillus subtilis grown on cassava wastewater. Bioresource Technology. 2006;97(2): 336-41.

[96] Panesar R, Panesar P, Bera M. Development of low cost medium for the production of biosurfactants. Asian Journal of Biotechnology. 2011.

[97] Thaniyavarn J, Chongchin A, Wanitsuksombut N, Thaniyavarn S, Pinphanichakarn P, Leepipatpiboon N, et al. Biosurfactant production by Pseudomonas aeruginosa A41 using palm oil as carbon source. The Journal of General and Applied Microbiology. 2006;52(4):215-22.

[98] Wan-Nawawi WMF, Jamal P, Alam MZ. Utilization of sludge palm oil as a novel substrate for biosurfactant production. Bioresource Technology. 2010;101(23):9241-7.

[99] Harayama S. Polycyclic aromatic hydrocarbon bioremediation design. Current Opinion in Biotechnology. 1997;8(3):268-73.

[100] Volkering F, Breure AM, van Andel JG, Rulkens WH. Influence of nonionic surfactants on bioavailability and biodegradation of polycyclic aromatic hydrocarbons. Applied and Environmental Microbiology. 1995;61(5):1699-705.

[101] Berg G, Seech AG, Lee H, Trevors JT. Identification and characterization of a soil bacterium with extracellular emulsifying activity. Journal of Environmental Science and Health Part A. 1990;25(7):753-64.

[102] Griffin R, Churchill P, Churchill S, Jones L. Biodegradation rate enhancement of hydrocarbons by an oleophilic fertilizer and a rhamnolipid biosurfactant. Journal of Environmental Quality. 1995;24(1):19-28. 
[103] Miller R. Surfactant-enhanced bioavailability of slightly soluble organic compounds. 1995.

[104] Deziel E, Paquette G, Villemur R, Lepine F, Bisaillon J. Biosurfactant production by a soil pseudomonas strain growing on polycyclic aromatic hydrocarbons. Applied and Environmental Microbiology. 1996;62(6):1908-12.

[105] Zhang Y, Maier WJ, Miller RM. Effect of rhamnolipids on the dissolution, bioavailability, and biodegradation of phenanthrene. Environmental Science and Technology. 1997;31(8):2211-7.

[106] Kanga SA, Bonner JS, Page CA, Marc A, Autenrieth RL. Solubilization of naphthalene and methyl-substituted naphthalenes from crude oil using biosurfactants. Environmental Science and Technology. 1997;31(2):556-61.

[107] Noordman WH, Ji W, Brusseau ML, Janssen DB. Effects of rhamnolipid biosurfactants on removal of phenanthrene from soil. Environmental Science and Technology. 1998;32(12):1806-12.

[108] Kuyukina MS, Ivshina IB, Makarov SO, Litvinenko LV, Cunningham CJ, Philp JC. Effect of biosurfactants on crude oil desorption and mobilization in a soil system. Environment International. 2005;31(2):155-61.

[109] Rahman K, Rahman T, Lakshmanaperumalsamy P, Marchant R, Banat I. The potential of bacterial isolates for emulsification with a range of hydrocarbons. Acta Biotechnologica. 2003;23(4):335-45.

[110] Inakollu S, Hung HC, Shreve GS. Biosurfactant enhancement of microbial degradation of various structural classes of hydrocarbon in mixed waste systems. Environmental Engineering Science. 2004;21(4):463-9.

[111] Kang SW, Kim YB, Shin JD, Kim EK. Enhanced biodegradation of hydrocarbons in soil by microbial biosurfactant, sophorolipid. Applied Biochemistry and Biotechnology. 2010;160(3):780-90.

[112] Das K, Mukherjee A. Differential utilization of pyrene as the sole source of carbon by Bacillus subtilis and Pseudomonas aeruginosa strains: role of biosurfactants in enhancing bioavailability. Journal of Applied Microbiology. 2007;102(1):195-203. 